\title{
Structural Health Monitoring with Piezoelectric Wafer Active Sensors for Space Applications
}

\author{
Adrian Cuc* and Victor Giurgiutiu \\ University of South Carolina, Columbia, South Carolina 29209 \\ and \\ Shiv Joshi \\ NextGen Aeronautics, Inc., Torrance, California 90505
}

DOI: $\underline{10.2514 / 1.26141}$

\begin{abstract}
Ultrasonic guided waves inspection using Lamb waves is suitable for damage detection in metallic structures. This paper will present experimental results obtained using guided Lamb waves to detect flaws in aluminum specimens with design features applicable to space applications. Two aluminum panels were fabricated from a variable-thickness aluminum top plate, with two bolted I-beams edge stiffeners and four bonded angle stiffeners. Artificial damages were introduced in the two panels: cracks, corrosions, and disbonds. The proposed investigation methods used bonded piezoelectric wafer active sensors to excite and receive Lamb waves. Three wave propagation methods were used: pitch-catch, pulse-echo, and the embedded ultrasonic structural radar. In addition, we also used a standing-wave damage detection technique, the electromechanical impedance method. The paper will present in detail the salient results from using these methods for damage detection and structural health monitoring. Where appropriate, comparison between different methods in detecting the same damage will be performed. The results have demonstrated the ability of piezoelectric wafer active sensors working in conjunction with guided Lamb waves to detect various types of damages present in complex geometry structures typical of space applications.
\end{abstract}

\section{Nomenclature}

$A_{0} \quad=$ antisymmetric Lamb-wave mode

$C=$ zero-load capacitance of the piezoelectric wafer active sensor

$D_{j} \quad=$ electrical displacement

$d_{k i j} \quad=$ piezoelectric coupling effect

$E_{k} \quad=$ electrical field

$S_{i j} \quad=$ mechanical strain

$S_{0} \quad=$ symmetric Lamb-wave mode

$s_{i j k l}^{E}=$ mechanical compliance

$T_{k l} \quad=$ mechanical stress

$Z=$ electromechanical impedance

$Z_{\mathrm{PWAS}}=$ electrical impedance of the piezoelectric wafer active sensor

$Z_{\text {str }} \quad=$ mechanical impedance of the structure

$\varepsilon_{j k}^{T}=$ dielectric permittivity at zero mechanical stress

$\kappa_{31}=$ electromechanical cross-coupling coefficient

\section{Introduction}

$\mathrm{S}^{\mathrm{T}}$ TRUCTURAL health monitoring (SHM) is an emerging research area with multiple applications. SHM assesses the state of structural health and, through appropriate data processing and interpretation, predicts the remaining life of the structure. There are many ultrasonic nondestructive evaluation, nondestructive inspec-

Received 24 June 2006; revision received 14 July 2007; accepted for publication 25 July 2007. Copyright (C) 2007 by Adrian Cuc; Victor Giurgiutiu. Published by the American Institute of Aeronautics and Astronautics, Inc., with permission. Copies of this paper may be made for personal or internal use, on condition that the copier pay the $\$ 10.00$ per-copy fee to the Copyright Clearance Center, Inc., 222 Rosewood Drive, Danvers, MA 01923; include the code 0001-1452/07 \$10.00 in correspondence with the CCC.

*Ph.D. Candidate, Department of Mechanical Engineering, 300 South Main Street.

${ }^{\dagger}$ Professor, Department of Mechanical Engineering, 300 South Main Street.

†Principal Engineer. Senior Member AIAA.

${ }^{\S}$ Independent Contractor, Garden Grove, CA 92845, Senior Engineer, 5351 Richmond Avenue. Lifetime Senior Member AIAA. tion, and nondestructive testing techniques for identifying local damage and detecting flaws in metallic structures. Ultrasonic nondestruction evaluation (NDE) methods rely on elastic wave propagation and reflection within the material. They try to identify the wave field disturbances due to local damage and flaws. Ultrasonic testing involves one or more of the following measurements: time of flight (TOF), path length, frequency, phase angle, amplitude, impedance, and angle of wave deflection (reflection and refraction). Conventional ultrasonic methods include the pulse-echo, the pitch-catch (or pulse-transmission), phased arrays, and the pulse-resonance techniques.

This paper will investigate and report on the possibility of using ultrasonic nondestructive evaluation methods and the opportunity for developing a structural health monitoring system for space applications on metallic structures. SHM determines the health of a structure by reading an array of sensors permanently attached on the structure and monitored over time. SHM can be either passive or active. Passive SHM infers the state of the structure using passive sensors that are monitored over time and fed into a structural model. Active SHM uses active sensors that interrogate the structure to detect the presence of damage, and to estimate its extent and intensity. One active SHM method employs piezoelectric wafer active sensors, which send and receive ultrasonic Lamb waves and determine the presence of cracks, delaminations, disbonds, and corrosions. Two approaches are being considered: 1) traveling waves, and 2) standing waves.

The novelty of this work represents the concept of a low-cost and lightweight damage detection system using permanently attached piezoelectric wafer active sensors in conjunction with guided Lamb waves used on realistic space-type application specimens. The system will permit continuous or on-demand structural damage assessment of the entire structure. The major finding of this research is the possibility of using combined ultrasonic methods to detect various types of induced damages on real-type application structures: pulse-echo, pitch-catch, phased arrays [embedded ultrasonics structural radar (EUSR)], and the electromechanical impedance. This work is based on the effort and the results the authors have achieved in the past several years [1-4] . Although much work has 


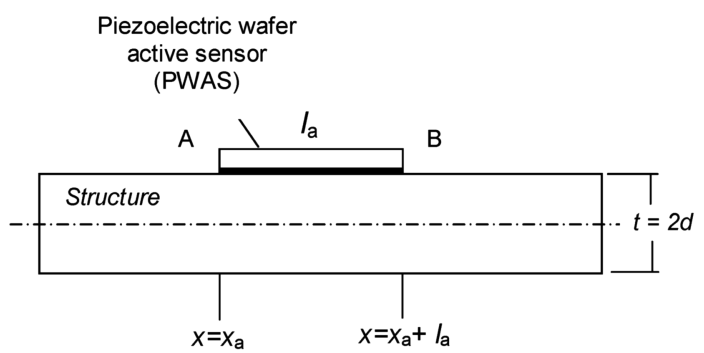

a)

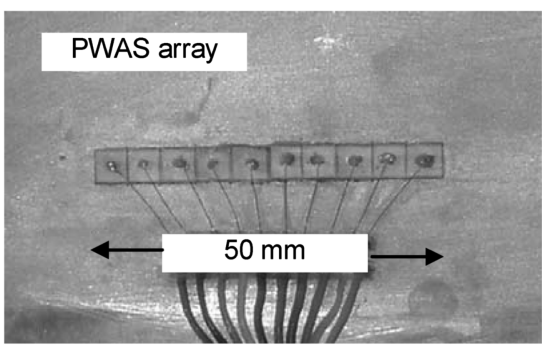

b)

Fig. 1 PWAS a) attached to the structure, b) rectangular shape array.

been done in the composite area [5-7], this study reports on results obtained solely on metallic structures.

\section{Piezoelectric Wafer Active Sensors}

Guided waves can be generated and detected using several methods. In conventional ultrasonic methods, guided waves are generated using large ultrasonic transducers that are usually positioned at an angle through a wedge. Another method to create guided waves is to use comb transducers. The comb spacing is such that it tunes with the guided half-wavelength.

The method used in this experiment to excite and receive guided waves uses piezoelectric wafer active sensors (PWAS), which are small unobtrusive transducers permanently attached to the structure [1,2] (Fig. 1a). PWAS are thin piezoelectric ceramic wafers, round or rectangular in shape (Fig. 1b), and are small, lightweight, and inexpensive compared with traditional ultrasonic transducers.

PWAS operate on the piezoelectric principle that couples the electrical and mechanical variables in the material (mechanical strain $S_{i j}$, mechanical stress $T_{k l}$, electrical field $E_{k}$, and electrical displacement $D_{j}$ ) in the form

$$
S_{i j}=s_{i j k l}^{E} T_{k l}+d_{k i j} E_{k} \quad D_{j}=d_{j k l} T_{k l}+\varepsilon_{j k}^{T} E_{k}
$$

where $S_{i j k l}^{E}$ is the mechanical compliance of the material measured at zero electric field $(E=0), \varepsilon_{j k}^{T}$ is the dielectric permittivity measured at zero mechanical stress $(T=0)$, and $d_{k i j}$ represents the piezoelectric coupling effect. When an applied stress on the sensor is converted into an electric charge, this phenomenon is called the direct piezoelectric effect. The inverse effect, conversely, will produce strain when a voltage is applied on the sensor. In this way, the PWAS can be used as both transmitter and receiver. For NDE applications, PWAS couple their in-plane motion, excited by the applied oscillatory voltage through the piezoelectric effect, with the Lamb-waves particle motion on the material surface. Lamb waves can be either quasi axial $\left(S_{0}, S_{1}, S_{2}, \ldots\right)$, or quasi flexural $\left(A_{0}, A_{1}, A_{2}, \ldots\right)$.

An important characteristic of PWAS, which distinguishes them from conventional ultrasonic transducers, is their capability of tuning into various guided-wave modes. Moulin et al. [] ] were among the first to realize the generation of Lamb waves with an attached piezoelectric disc. Using finite element modeling and experimental results, they showed the excitation of $S_{0}, S_{1}, A_{0}, A_{1}$, and $A_{2}$ Lamb waves at up to $2.5 \mathrm{MHz}$ frequencies. Lin and Yuan [9] studied the use of piezoceramic discs for generation and detection of circular-crested flexural waves in a composite plate using the Mindlin theory. The solution was derived in terms of Henkel functions. Propagation of smoothed tone bursts was also studied. The theoretical predictions compared favorably with experimental measurements. Liu et al. [10] investigated the input-output characteristic of piezoelectric structural health monitoring systems for composite plates. Lee and Staszewski $[11,12]$ used finite differences and local interaction simulation approach (LISA) to model the generation of Lamb waves with surface-mounted piezoceramic wafers for the detection of

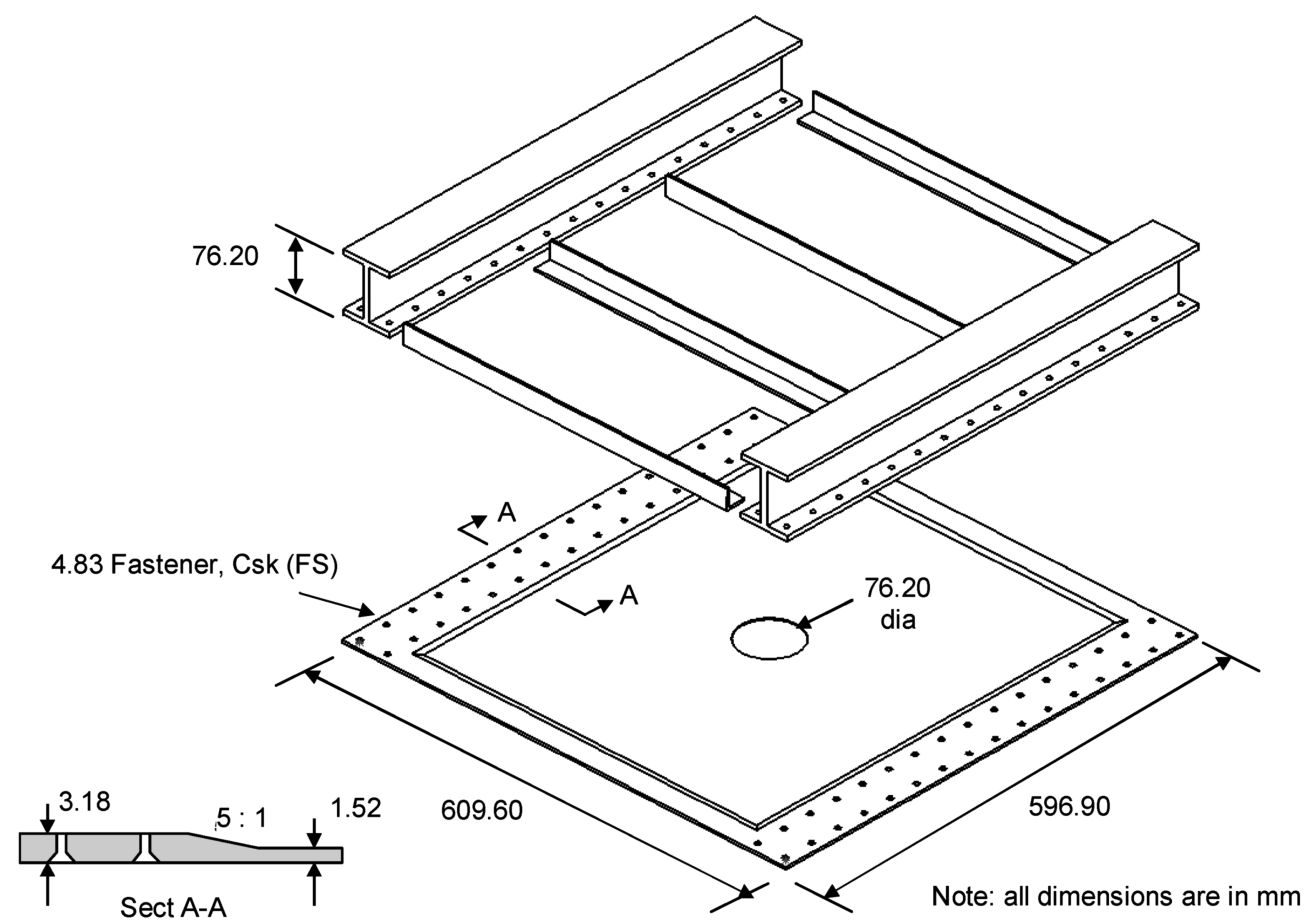

Fig. 2 Structural panel design. 
Table 1 Induced panel damages

\begin{tabular}{lccc}
\hline \hline Panel 1 & & & Panel 2 \\
\hline ID & Size, mm & ID & Size, mm \\
\hline CK1 & $19.05 \times 0.38 \times$ thru thickness & CB1 & $93.98 \times 0.38 \times$ thru thickness \\
CK2 & $12.70 \times 0.38 \times$ thru thickness & CB2 & $8.89 \times 0.38 \times$ thru thickness \\
CK3 & $12.70 \times 0.38 \times$ thru thickness & CB3 & $17.78 \times 0.38 \times$ thru thickness \\
CK4 & $12.70 \times 0.38 \times$ thru thickness & CB4 & $8.89 \times 0.38 \times$ thru thickness \\
CR1 & $41.91 \times 9.65 \times 0.64$ & CB5 & $17.78 \times 0.38 \times$ thru thickness \\
CR2 & $12.70 \times 9.65 \times 0.64$ & CB6 & $17.78 \times 0.38 \times$ thru thickness \\
DB1 & $50.80 \times 12.70$ & CR1 & $58.42 \times 12.70 \times 0.64$ \\
DB2 & $25.40 \times 25.40$ & CR2 & $50.80 \times 12.70 \times 0.64$ \\
DB3 & $50.80 \times 12.70$ & - & - \\
DB4 & $25.40 \times 25.40$ & - & - \\
\hline \hline
\end{tabular}

structural damage. Numerical simulation compared favorably with experiments. Lin et al. [13] reported experimental results indicating that the piezoelectric transducers effectiveness in exciting $A_{0}$ and $S_{0}$ Lamb modes varies significantly with the PWAS location across the laminate thickness.

Although a complete modeling of this interaction is not yet available, some simplified models exist that clarify the underlying principles of Lamb-wave tuning with PWAS transducers. Giurgiutiu [14] developed a plane-strain analysis of the PWAS-structure interaction using the space-domain Fourier analysis. This model illustrates the principles of PWAS Lamb-wave mode tuning, and opens the path for a more comprehensive analysis.

\section{Spacecraft Panels}

Two aluminum test panels were fabricated by NextGen Aeronautics, Inc. The panels consist of the skin (Al 7075, $609.60 \times 596.90 \times 3.18 \mathrm{~mm}$ ) with a 76.2-mm-diam hole in the center, two spars (Al 6061 I-beams, $76.20 \times 63.50 \times 6.35 \mathrm{~mm}$ and $609.60 \mathrm{~mm}$ length), four stiffeners (Al 6063, $25.40 \times 25.40 \times$ $3.18 \mathrm{~mm}$ and $469.90 \mathrm{~mm}$ length), and fasteners installed from the skin side (Fig. 2).

The stiffeners were bonded to the aluminum skin using a structural adhesive, Hysol EA 9394. Damages were artificially introduced in the two specimens including cracks (CK), corrosions (CR), disbonds (DB), and cracks under bolts (CB). A summary of the type and size of the damages is provided in Table 1 .
A schematic of the aluminum panel 1 specimen showing the location of the damage is presented in Fig. 3. Panel 1 contains disbonds, cracks, and corrosions. The disbonds are located between the stiffeners and the skin. They are of two types: partial disbonds DB1 and DB3, and complete disbonds DB2 and DB4. The corrosion damages were simulated as machined areas were part of material that was removed. The four cracks presented are in the shape of a slit and are through cracks located on the skin of the panel.

The two panels were instrumented with piezoelectric wafer active sensors as shown in Fig. 3. The PWAS are used for both sensing and receiving Lamb waves. The location and the number of sensors is dependant on the detection method. The pitch-catch detection method is based on wave propagation and should be used for the detection of disbonds. The method works best on thin plates and shells with relatively little curvature. Circular PWAS wafers with a $7 \mathrm{~mm}$ diameter and a thickness of $0.2 \mathrm{~mm}$ should be used. The placement of PWAS sensors depends on the type and resolution of damage to be detected. As a general rule, PWAS should be located within $50 \mathrm{~mm}$ of the critical area: typically near the edge of a bond. The pulse-echo detection method is also based on wave propagation, but can be used for the detection of both disbonds and cracks. Circular PWAS wafers with a 7-mm-diam and $0.2 \mathrm{~mm}$ thickness should be used as well. PWAS can be located up to $200 \mathrm{~mm}$ from the critical area if the stiffness is relatively constant. To detect damage on a panel, sensors should be located near the edge of the panel. For damage in large stiffness areas (under large stiffeners or pad-ups), sensors should be located along the centerline of the feature (i.e., along the spar or rib). For cracks, an array of at least three sensors

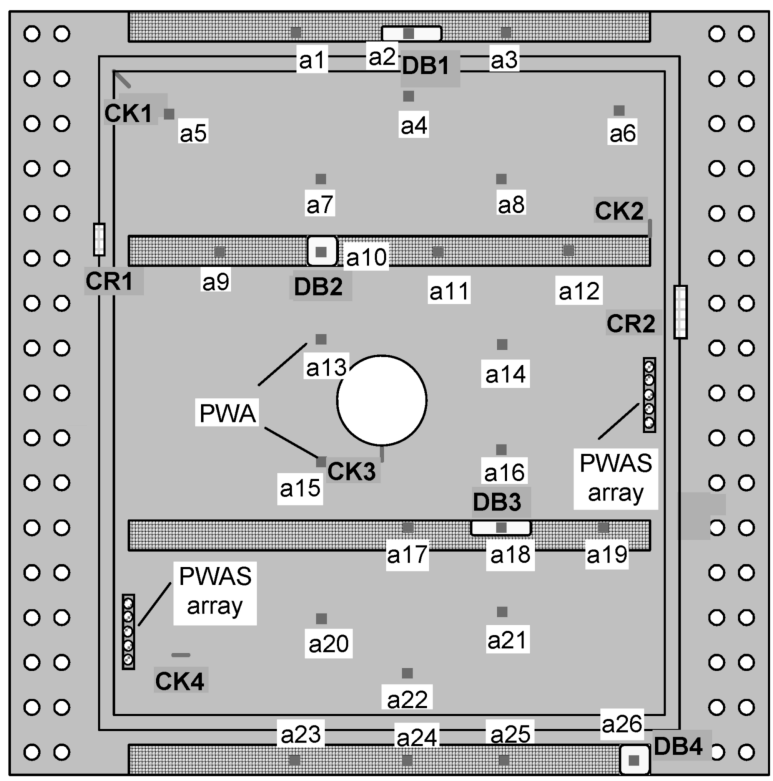

a)

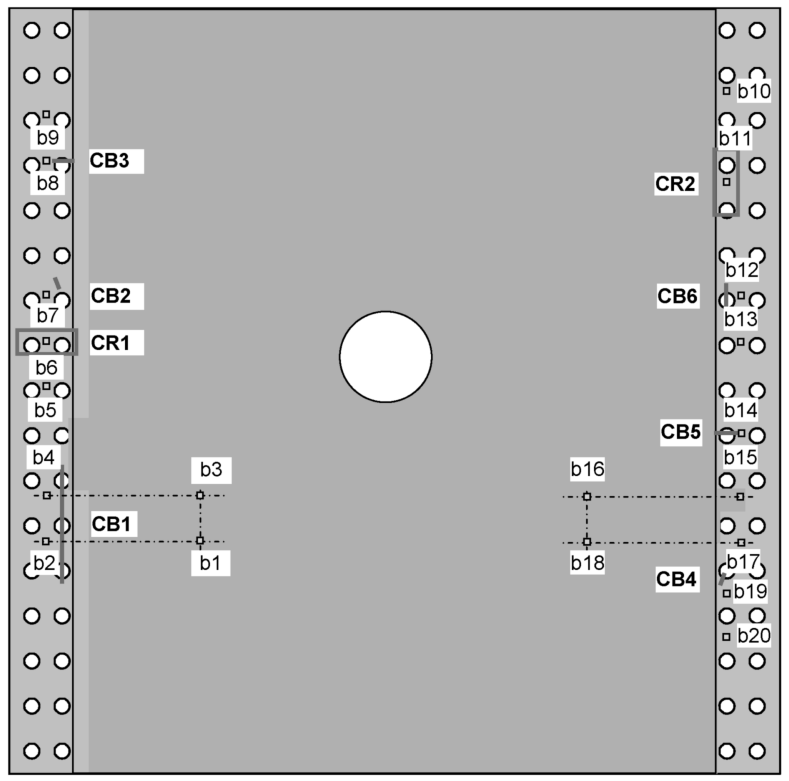

b)

Fig. 3 Schematic of the location and the type of the damage a) on the panel 1 specimen (top view), and b) on the panel 2 specimen (bottom view). 

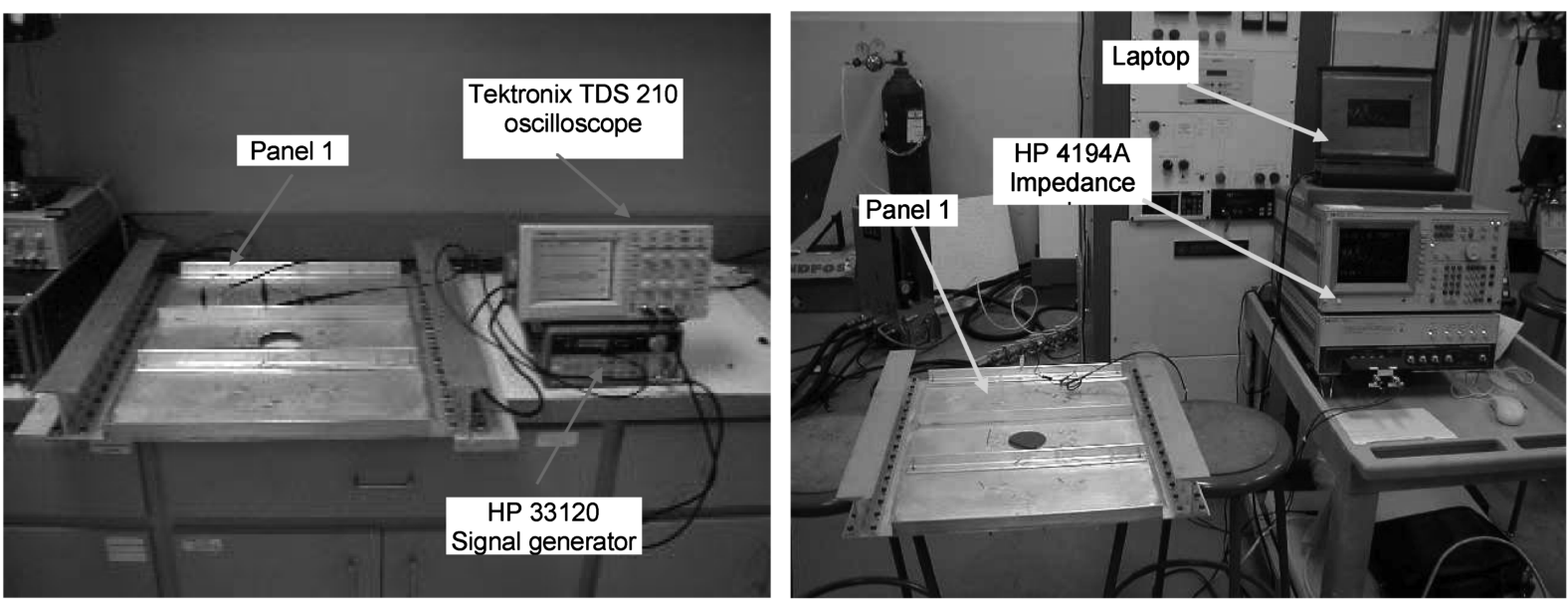

a)

b)

Fig. 4 Instrumentation setup for a) wave propagation, b) electromechanical impedance.

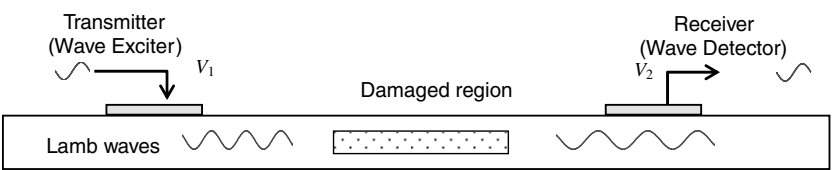

Fig. 5 Ultrasonic damage detection using PWAS: pitch-catch method.

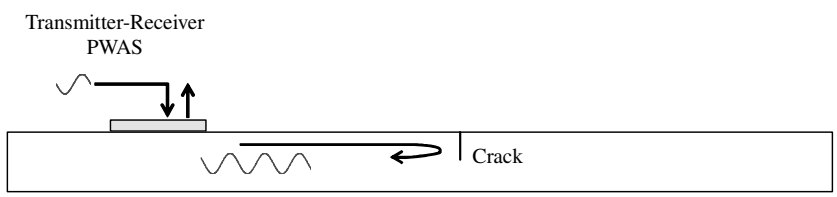

Fig. 6 Ultrasonic damage detection using PWAS: pulse-echo method.

should be used in conjunction with the EUSR algorithm (embedded ultrasonic structural radar). PWAS sensors should be installed after the part is assembled to minimize potential sensor damage, but they could be installed on a part before assembly if necessary. Finding the exact location or the optimum location of the sensors on the specimens was not part of the objectives of the present work and hence not investigated. Other authors have considered the location of the sensors and reported results in their work $[15,16]$.

In applications where the location of the damage is not known, the method of choice would be the EUSR, which gives the possibility of scanning large areas for various types of defects. The advantage of the EUSR is that it uses a localized array of sensors and through proper tuning is able to scan a large area of the specimen. When the location of the damage is not determined, the "hot spots" that are known to be prone to damage will be instrumented with sensors arrays.

The experimental setup is presented in Fig. 4. An HP 33120 signal generator was used to excite the sensors with a three-count sine smoothed burst signal at a frequency of $330 \mathrm{kHz}$. The received signal was displayed on a Tektronix TDS 210 digital oscilloscope and transferred to a laptop. For the electromechanical impedance method, the instrumentation setup is shown in Fig. 4b. The real part of the EM impedance spectrum was recorded using an HP 4194A impedance analyzer. The frequency range of the excitation was from $150 \mathrm{kHz}$ to $1.5 \mathrm{MHz}$.

\section{Detection Strategies}

In the experiments conducted in this study, a significant number of PWAS transducers were initially used to ensure a good signal response near known damage locations. The detection capabilities used were 1) wave propagation, which includes pitch-catch (disbond detection), pulse-echo (disbond and crack detection), and embedded ultrasonic structural radar (crack detection); and 2) standing waves, which includes electromechanical impedance (E/M) (disbond, crack, and corrosion detection).

Damage in real life occurs from very small cracks that can develop faster or slower depending on the environment and the working regime, and can lead to catastrophic failure. In our study, we are interested in detecting damages of such sizes that are in the range of 3-5 level of damage and can cause catastrophic failures. Incipient damage detection was not part of the objectives of this research, although previous work was conducted in this direction [17]. Of interest to the industrial community is the ability to determine, based on the size of the damage and the growth rate, how much life the structure still has. The work we conducted addresses the first part: detection of significant damage in various forms to the structure.

\section{A. Pitch-Catch Method}

The pitch-catch method can be used to detect structural changes that take place between a transmitter transducer and a receiver transducer. The detection is performed through the examination of the guided-wave amplitude, phase, dispersion, and time of flight in comparison with a "pristine" situation. Guided-wave modes that are strongly influenced by small changes in the material stiffness and thickness (such as the $A_{0}$ Lamb wave) are well suited for this method. Typical applications include 1) corrosion detection in metallic structures, 2) diffused damage in composites, 3) disbond detection in adhesive joints, 4) delamination detection in layered composites, etc. The pitch-catch method can also be used to detect the presence of cracks from the wave signal diffracted by the crack.

The pitch-catch method detects damage from the changes Lamb waves undergo when traveling through a damaged region. The method uses the transducers in pairs: one acts as transmitter, and the other as receiver. In the embedded pitch-catch method (Fig. 5), the transducers are either permanently attached to the structure or inserted between the layers of composite lay-up.

\section{B. Pulse-Echo Method}

In conventional NDE, the pulse-echo method has traditionally been used for through-the-thickness testing. For large area inspection, through-the-thickness testing requires manual or mechanical moving of the transducer over the area of interest, which is labor intensive and time consuming. For this type of application, it seems that guided-wave pulse-echo methods are more appropriate, because wide coverage could be achieved from a single location.

For crack detection with the pulse-echo method, an appropriate Lamb-wave mode must be selected. Giurgiutiu [14] used finite element simulation to show that the $S_{0}$ Lamb waves can give much 


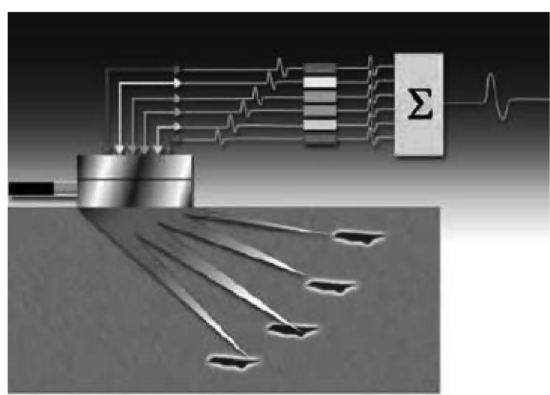

a)

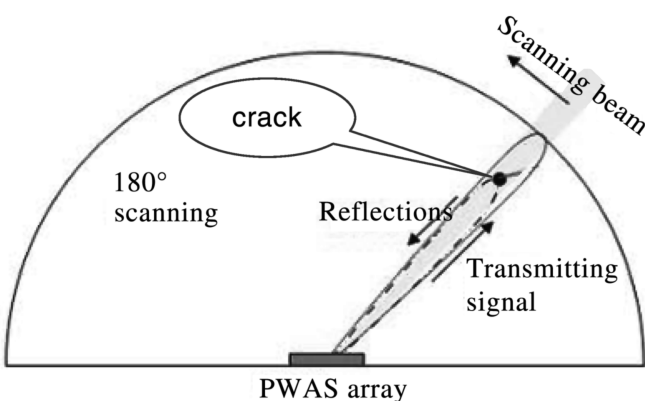

b)

Fig. 7 Phased array a) conventional (GE Inspection Technology), and b) EUSR PWAS.

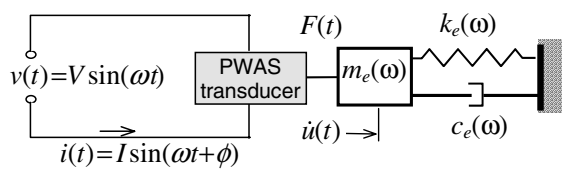

Fig. 8 Ultrasonic damage detection using PWAS: E/M impedance method.

better reflections from through-the-thickness cracks than the $A_{0}$ Lamb waves. This effect can be attributed to $S_{0}$ being 1) better reflected from the crack, and 2) much less dispersive. The first fact gives a strong signal, whereas the second ensures that the wave packet is compact and easy to interpret.

The use of Lamb-wave pulse-echo methods with bonded PWAS follows the general principles of conventional Lamb-wave NDE. A PWAS transducer attached to the structure acts as both transmitter and receiver of acoustic guided waves traveling in the structure. If damage is in the path of the traveling wave (i.e., crack), then the wave sent by the PWAS is partially reflected at the crack. The echo is captured at the same PWAS acting as receiver (Fig. 6). For the method to be successful, it is important that a low-dispersion Lamb wave is used. The selection of such a wave, e.g., the $S_{0}$ mode, is achieved through the Lamb-wave tuning methods [14].

\section{Embedded Ultrasonic Structural Radar}

Real-time phased-array systems have become very popular in NDE practice. Giurgiutiu and Bao [18] developed a PWAS phasedarray application and named it embedded ultrasonic structural radar (EUSR). Its principle of operation is derived from two general concepts: the guided Lamb-wave generation with piezoelectric wafer active sensors (PWAS), and the principles of conventional phasedarray radar (Fig. 7).

Table 2 Test matrix

\begin{tabular}{|c|c|c|c|c|c|c|}
\hline \multirow[t]{2}{*}{ Method } & \multicolumn{2}{|c|}{ Sensor no. } & \multicolumn{2}{|r|}{ Excitation } & \multirow[t]{2}{*}{ Mode } & \multirow[t]{2}{*}{ Damage } \\
\hline & Transmitter & Receiver & Freq., $\mathrm{kHz}$ & Amplitude, V (peak to peak) & & \\
\hline \multirow[t]{8}{*}{ Pitch-catch } & $\mathrm{a} 1$ & a3 & 110 & 10 & So & DB1 \\
\hline & a9 & a11 & 110 & 10 & S0 & DB2 \\
\hline & a17 & a19 & 110 & 10 & So & DB3 \\
\hline & a23 & a25 & 110 & 10 & S0 & $\mathrm{C}$ \\
\hline & a7 & a13 & 110 & 10 & S0 & DB2 \\
\hline & a8 & a14 & 110 & 10 & So & $\mathrm{C}$ \\
\hline & $\mathrm{a} 20$ & a15 & 110 & 10 & So & $\mathrm{C}$ \\
\hline & $\mathrm{a} 21$ & a16 & 110 & 10 & So & DB3 \\
\hline \multirow[t]{20}{*}{ Pulse-echo } & \multicolumn{2}{|c|}{ a5 } & 110 & 10 & S0 & CK1 \\
\hline & \multicolumn{2}{|c|}{ a6 } & 110 & 10 & So & $\mathrm{C}$ \\
\hline & \multicolumn{2}{|c|}{ a1 } & 110 & 10 & So & DB1 \\
\hline & \multicolumn{2}{|c|}{ a3 } & 110 & 10 & S0 & DB1 \\
\hline & \multicolumn{2}{|l|}{ a4 } & 110 & 10 & S0 & DB1 \\
\hline & \multicolumn{2}{|c|}{ a7 } & 110 & 10 & So & DB2 \\
\hline & \multicolumn{2}{|c|}{ a13 } & 110 & 10 & So & DB2 \\
\hline & \multicolumn{2}{|c|}{ a9 } & 110 & 10 & S0 & DB2 \\
\hline & \multicolumn{2}{|c|}{ a12 } & 110 & 10 & So & $\mathrm{C}$ \\
\hline & \multicolumn{2}{|c|}{ a8 } & 110 & 10 & S0 & $\mathrm{C}$ \\
\hline & \multicolumn{2}{|c|}{ a14 } & 110 & 10 & S0 & $\mathrm{C}$ \\
\hline & \multicolumn{2}{|c|}{ a16 } & 110 & 10 & So & DB3 \\
\hline & \multicolumn{2}{|c|}{ a21 } & 110 & 10 & S0 & DB3 \\
\hline & \multirow{2}{*}{\multicolumn{2}{|c|}{ a17 }} & 110 & 10 & So & DB3 \\
\hline & & & 110 & 10 & So & $\mathrm{C}$ \\
\hline & \multicolumn{2}{|c|}{$\begin{array}{l}\text { a19 } \\
\text { a15 }\end{array}$} & 110 & 10 & So & $\mathrm{C}$ \\
\hline & \multicolumn{2}{|c|}{ a20 } & 110 & 10 & S0 & $\mathrm{C}$ \\
\hline & \multicolumn{2}{|c|}{$\mathrm{a} 23$} & 110 & 10 & S0 & $\mathrm{C}$ \\
\hline & \multirow{2}{*}{\multicolumn{2}{|c|}{$\begin{array}{l}\mathrm{a} 25 \\
\mathrm{a} 22\end{array}$}} & 110 & 10 & So & DB4 \\
\hline & & & 110 & 10 & S0 & $\mathrm{C}$ \\
\hline \multirow[t]{7}{*}{ E/M Imped. } & & - & - & 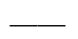 & DB1 \\
\hline & a5 & & - & - & 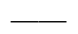 & CK1 \\
\hline & a6 & & 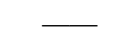 & 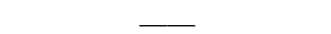 & 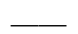 & C \\
\hline & a10 & & - & - & - & $\mathrm{DB} 2$ \\
\hline & a18 & & - & - & - & DB3 \\
\hline & $\mathrm{a} 24$ & & - & - & - & $\mathrm{C}$ \\
\hline & a26 & & - & - & - & DB4 \\
\hline
\end{tabular}



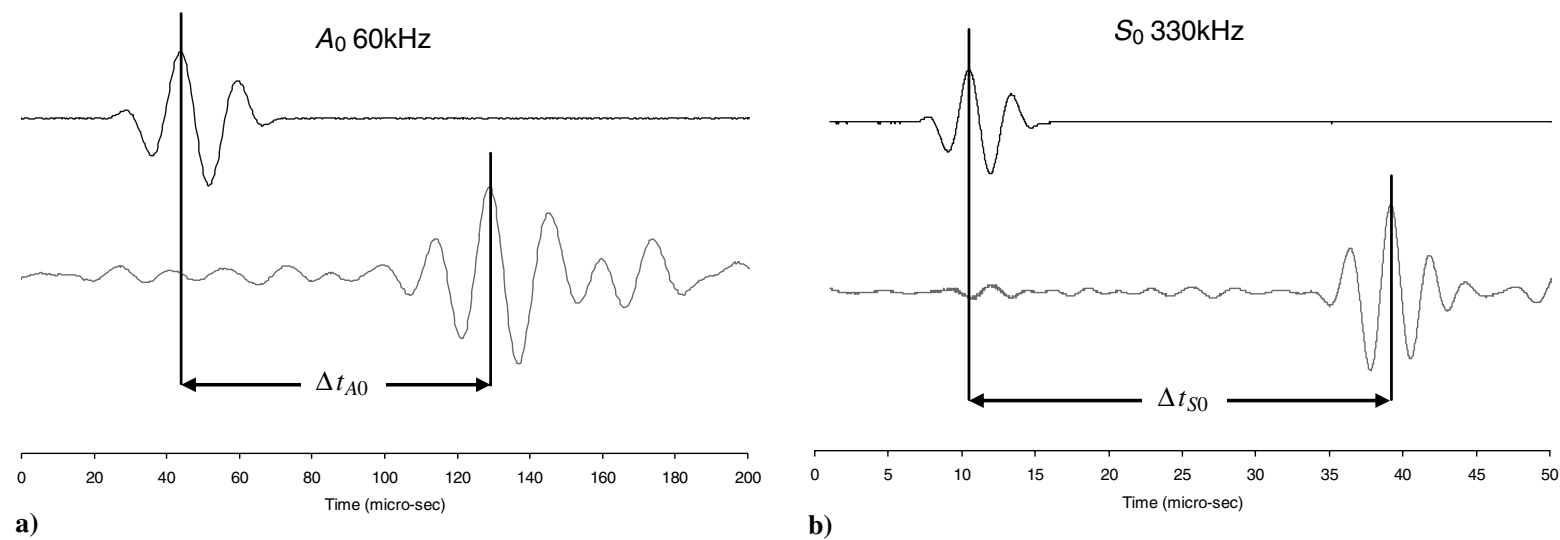

Fig. 9 Time of flight for the wave transmitted from PWAS no. 1 to arrive at PWAS no. 2 when a) the $A_{0}$ Lamb mode was excited, and b) the $S_{0}$ Lamb mode was excited.

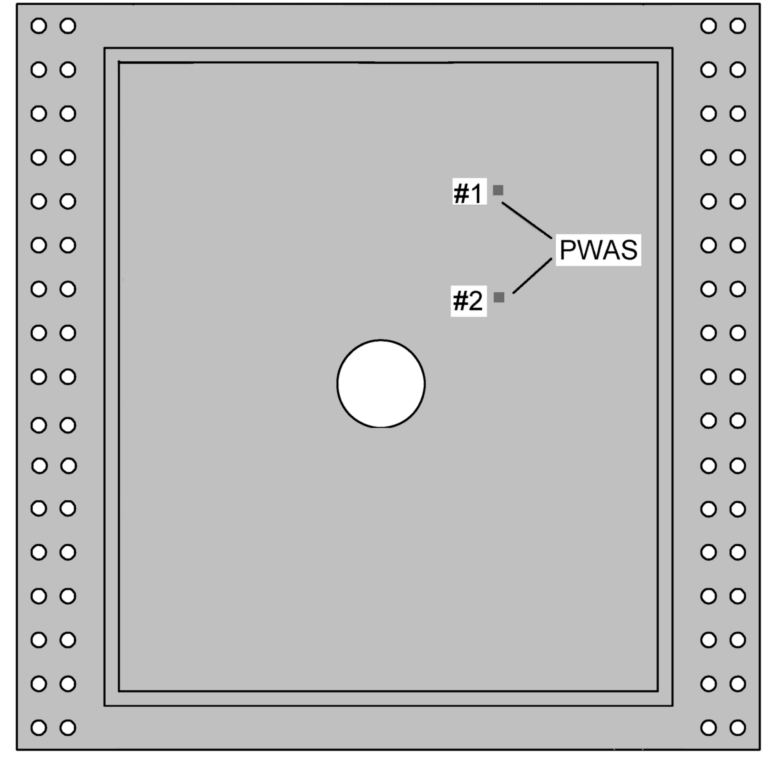

Fig. 10 PWAS location used to calculate the $A_{0}$ and $S_{0}$ Lamb modes wave speed.
The EUSR approach is different from the conventional phasedarray approach in two aspects: 1) it can use attached or embedded PWAS transducers, and 2) it works in virtual time, not in real time.

Of these two, the latter is most important for structural health monitoring, because it permits the phased-array benefits without the drawback of real-time multiple channel phasing. Whereas real-time phased-array transducers require heavy and complex multichannel phasing equipment, the virtual-time approach adopted by the EUSR method can be done with only one channel and very simple equipment.

The principles of conventional phased-array radar [19] are applied to the EUSR algorithm assuming a uniform linear array of $M$ transmitter/receivers PWAS, where each PWAS acts as a pointwise omnidirectional source/sink. The PWAS in the array are spaced at the distance $d=\lambda / 2$, which is assumed much smaller than the distance $r$ to a generic, far-distance point $P$. Because $d \ll r$, the rays joining the sensors with the point $P$ can be assimilated with a parallel fascicle, of angle $\phi$. Therefore, for the $m$ th PWAS, the distance will be shortened by $m(d \cos \phi)$. If all the PWAS are fired simultaneously, the signal from the $m$ th PWAS will arrive at $P$ quicker by $\Delta_{m}(\phi)=m(d \cos \phi) / c$. Yet, if the PWAS are not fired simultaneously, but with some individual delays, $\delta_{m}$, $m=0,1, \ldots, M-1$, then the total signal received at point $P$ will be

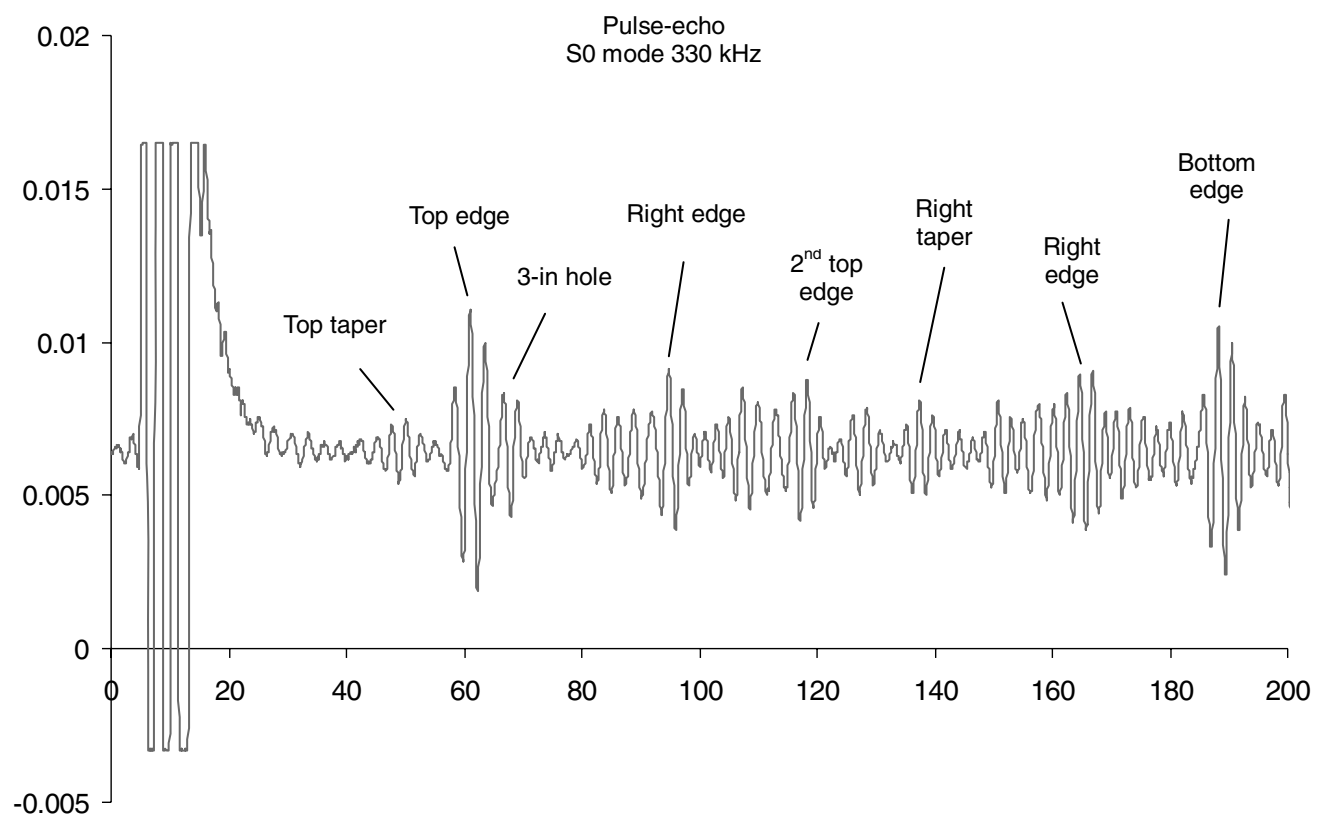

Time (micro-sec)

Fig. 11 Pulse-echo method: received signal at PWAS no. 1. 


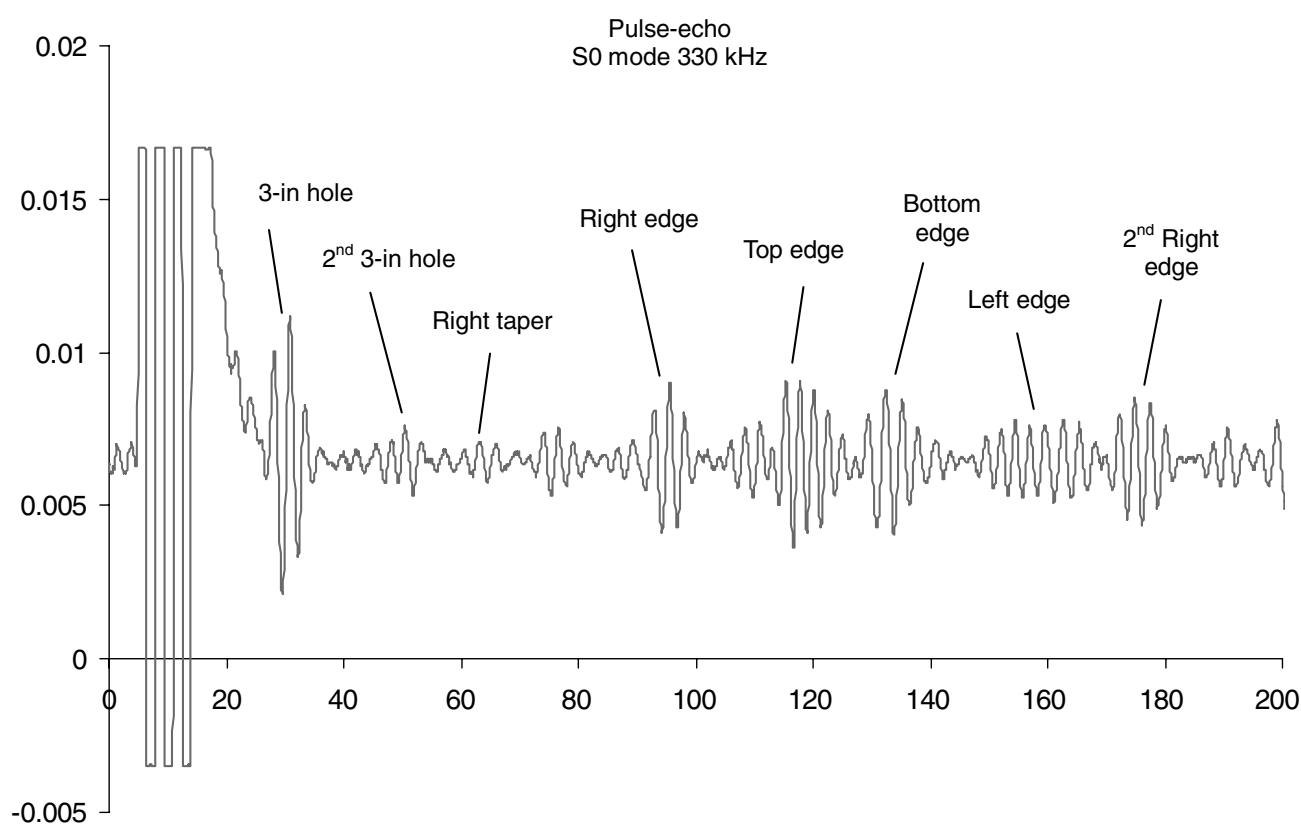

Time (micro-sec)

Fig. 12 Pulse-echo method: received signal at PWAS no. 2.

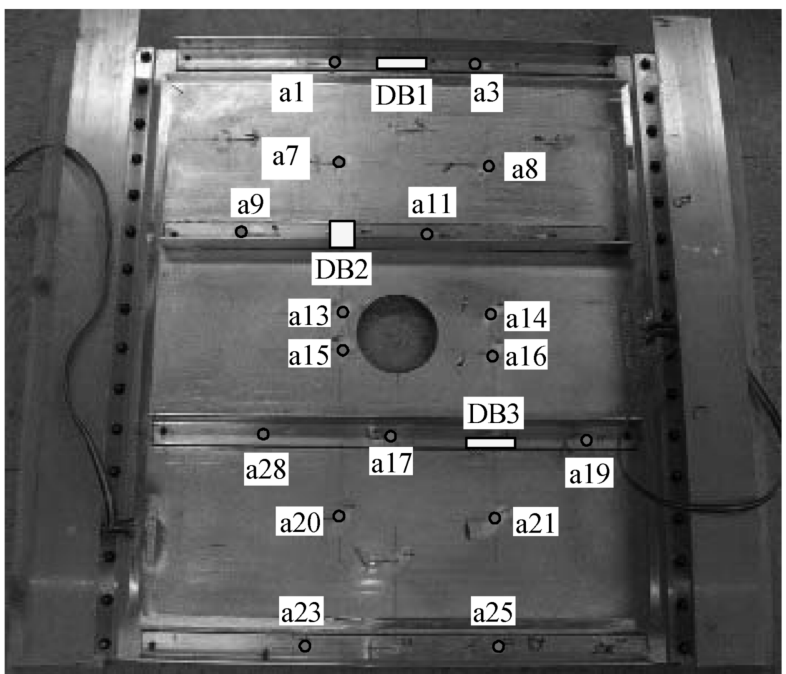

a)

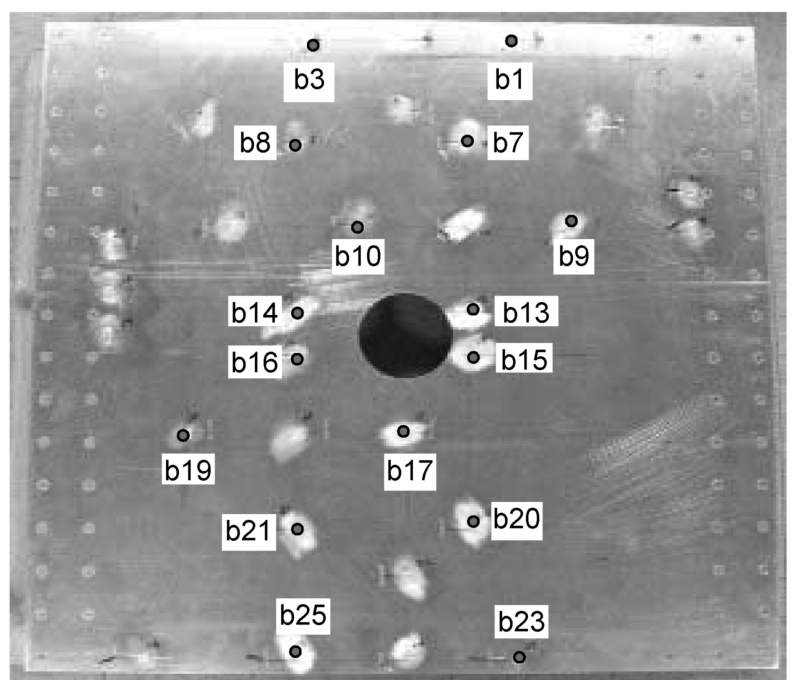

b)

Fig. 13 PWAS location on panel 1 for pitch-catch tests: a) top face of panel 1, and b) bottom face of panel 1.

$$
s_{P}(t)=\frac{1}{\sqrt{r}} \sum_{m=0}^{M-1} s_{T}\left(t-\frac{r}{c}+\Delta_{m}(\phi)-\delta_{m}\right)
$$

where $1 / \sqrt{r}$ represents the decrease in the wave amplitude due to the omnidirectional two-dimensional radiation, and $r / c$ is the delay due to the travel distance between the reference PWAS $(m=0)$ and the point $P$. (It is important to note that wave-energy conservation with no dissipation is assumed.)

\section{Electromechanical Impedance Method}

The impedance method is a damage detection technique complementary to the wave propagation techniques. The mechanical impedance method consists of exciting vibrations of bonded plates using a specialized transducer that simultaneously measures the applied normal force and the induced velocity.
The electromechanical impedance method is an emerging technology that offers distinctive advantage over the mechanical impedance method. Whereas the mechanical impedance method uses normal force excitation, the E/M impedance method uses inplane strain. The mechanical impedance transducer measures mechanical quantities (force and velocity/acceleration) to indirectly calculate the mechanical impedance, whereas the E/M impedance active sensor measures the E/M impedance directly as an electrical quantity. The principles of the E/M impedance technique are illustrated in Fig. 8 .

The effect of a piezoelectric wafer active sensor affixed to the structure is to apply a local strain parallel to the surface that creates stationary elastic waves in the structure. The structure presents to the active sensor the drive-point impedance, $Z_{\text {str }}(\omega)=i \omega m_{e}(\omega)+$ $c_{e}(\omega)-i k_{e}(\omega) / \omega$. Through the mechanical coupling between the PWAS and the host structure, on one hand, and through the electromechanical transduction inside the PWAS, on the other hand, 


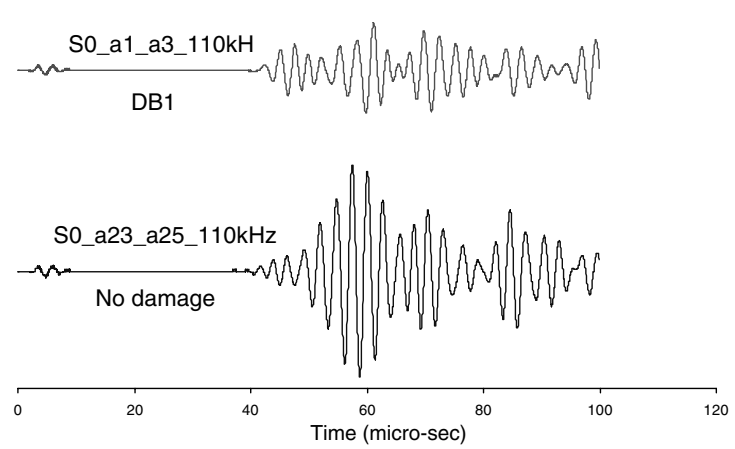

a)
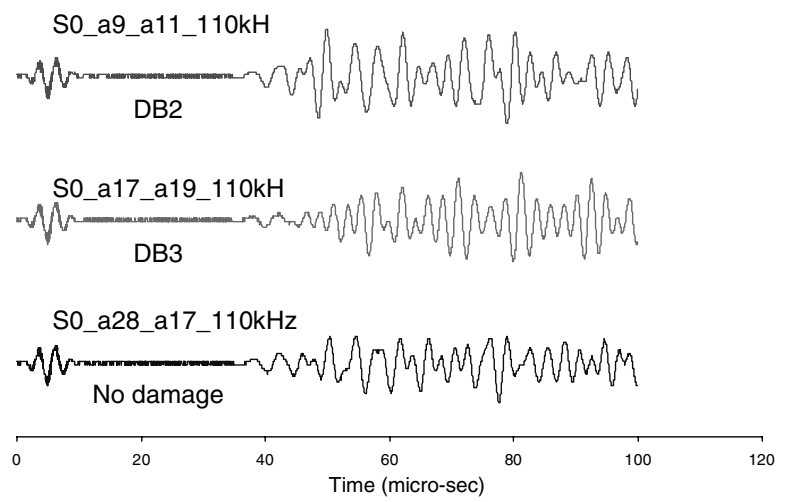

b)

Fig. 14 Pitch-catch method: a) signal traveling over the disbond DB1; b) signals traveling over the disbond DB2 and DB3.

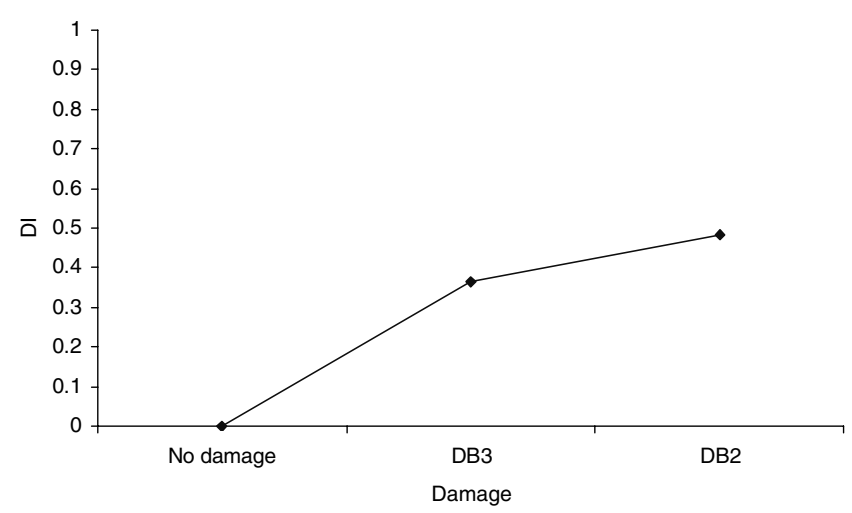

Fig. 15 Damage index of the three signals showing an increase of the DI with the severity of the damage.

the drive-point structural impedance is directly reflected into the effective electrical impedance as seen at the active sensor terminals. The apparent electromechanical impedance of the piezoelectric active sensor as coupled to the host structure is

$$
Z(\omega)=\left[i \omega C\left(1-\kappa_{31}^{2} \frac{Z_{\mathrm{str}}(\omega)}{Z_{\mathrm{PWAS}}(\omega)+Z_{\mathrm{str}}(\omega)}\right)\right]^{-1}
$$

where $Z(\omega)$ is the equivalent electromechanical admittance as seen at the PWAS terminals, $C$ is the zero-load capacitance of the PWAS, $\kappa_{31}$ is the electromechanical cross-coupling coefficient of the PWAS $\left(\kappa_{31}=d_{13} / \sqrt{\bar{s}_{11} \bar{\varepsilon}_{33}}\right), Z_{\text {str }}$ is the impedance of the structure, and $Z_{\text {PWAS }}$ is the impedance of the PWAS. The electromechanical impedance method is applied by scanning a predetermined frequency range in the hundreds of kilohertz band and recording the complex impedance spectrum. By comparing the impedance spectra taken at various times during the service life of a structure, meaningful information can be extracted pertinent to structural degradation and the appearance of incipient damage. It must be noted that the frequency range must be high enough for the signal wavelength to be significantly smaller than the defect size.

\section{Experimental Results}

For consistency and a straightforward data collection and data manipulation, a test matrix was developed. A sample of the test matrix for data collection from the PWAS is presented in Table 2.

\section{A. Piezoelectric Wafer Active Sensors Calibration}

The geometry of the piezoelectric wafer has an effect on the desired performance. A wafer with length $l$, width $b$, and thickness $h$ that are widely separated $(h \ll b \ll 1)$ will predominantly exhibit one-dimensional motion in the direction of length. PWAS are capable of geometric tuning through matching between their characteristic direction and the half-wavelength of the exited Lamb mode. Rectangular shaped PWAS with high length-to-width ratio can generate unidirectional Lamb waves through half-wavelength tuning in the length direction. Circular PWAS excite omnidirectional Lamb waves that propagate in circular wave fronts. Omnidirectional
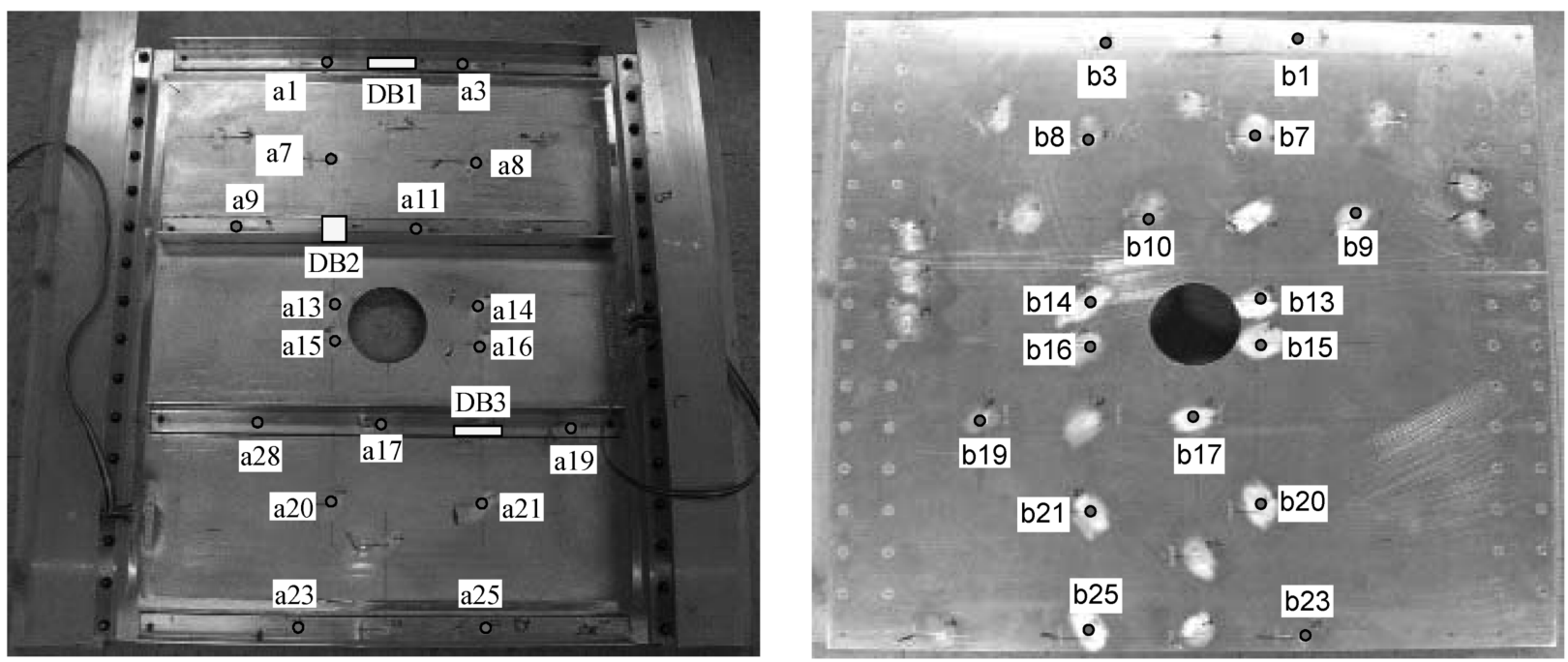

a)

b)

Fig. 16 PWAS location on panel 1, pulse-echo method: a) top face of Panel 1, and b) bottom face of panel 1. 


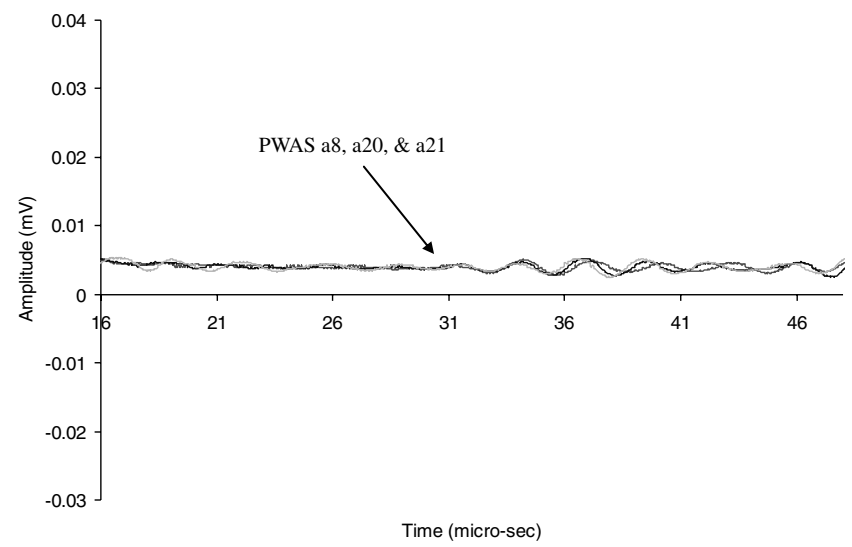

Fig. 17 Pulse-echo method: pristine data from PWAS a8, a20, and a21 showing a good consistent response.

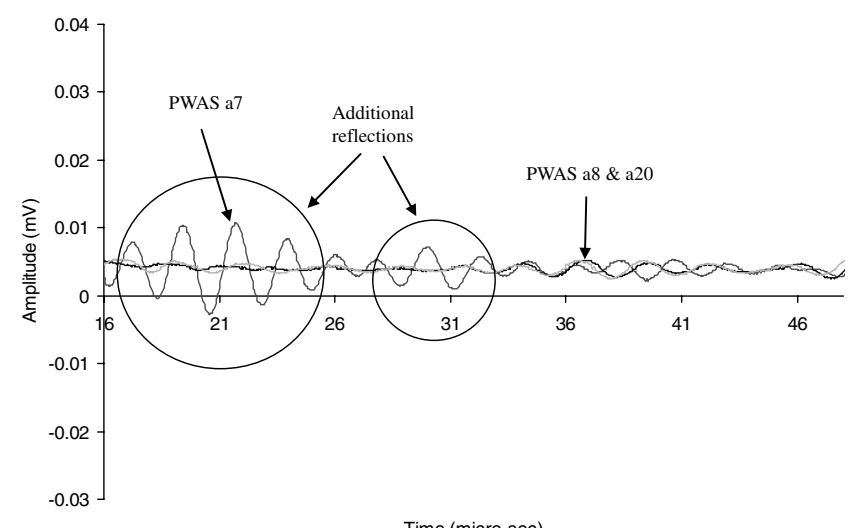

Fig. 18 Pulse-echo method: additional reflections due to the presence of damage.

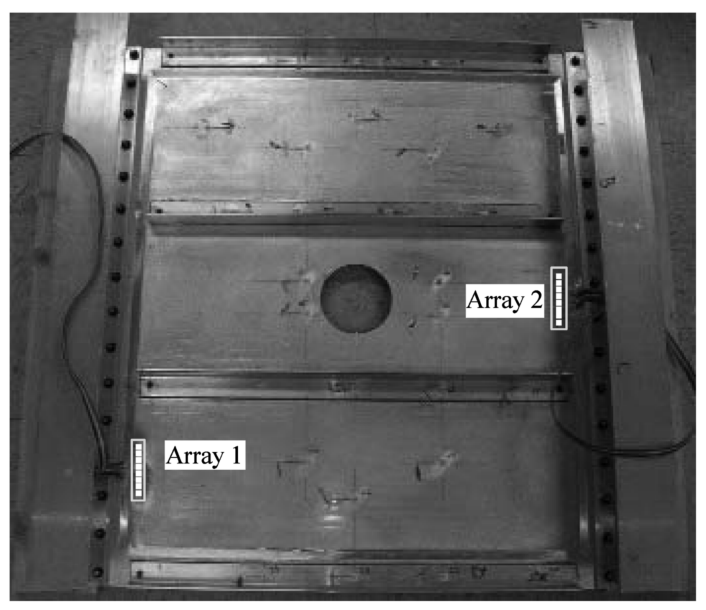

Fig. 19 PWAS arrays locations on panel 1 for the EUSR tests.

Lamb waves are also generated by square PWAS, although their pattern is somehow irregular in the PWAS proximity. At far enough distance, the wave front generated by square PWAS is practically identical with that generated by circular PWAS.

Among the factors that can affect PWAS calibration, we considered 1) environment, and 2) adhesive bond layer. The influence of the neighboring sensors may also be important, but most of our sensors were sparsely placed. The influence of specimen-free edges is important in certain cases, but this effect does not apply to the investigative approach used in this study.

The environment can have an effect on the sensors and needs to be taken into account when sensors are calibrated and when bonding methods are selected. In previous work $[20,21]$, this effect was studied and evaluated extensively. The results showed that repeated differential thermal expansion and extended environmental attacks can lead to PWAS failure. This emphasizes the importance of achieving proper adhesion between the PWAS and the structure, and

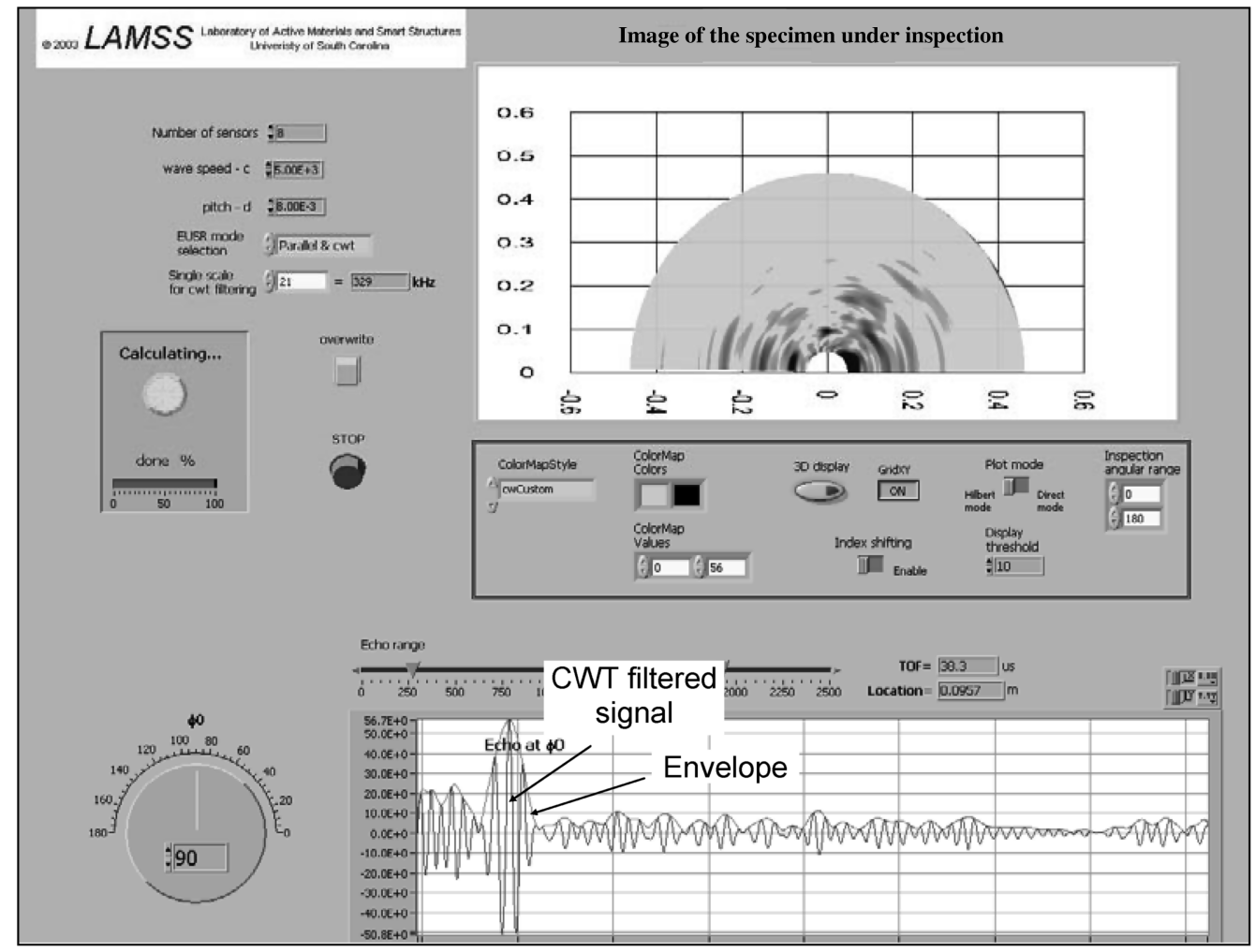

Fig. 20 EUSR inspection result of the array no. 1, plate 1. 


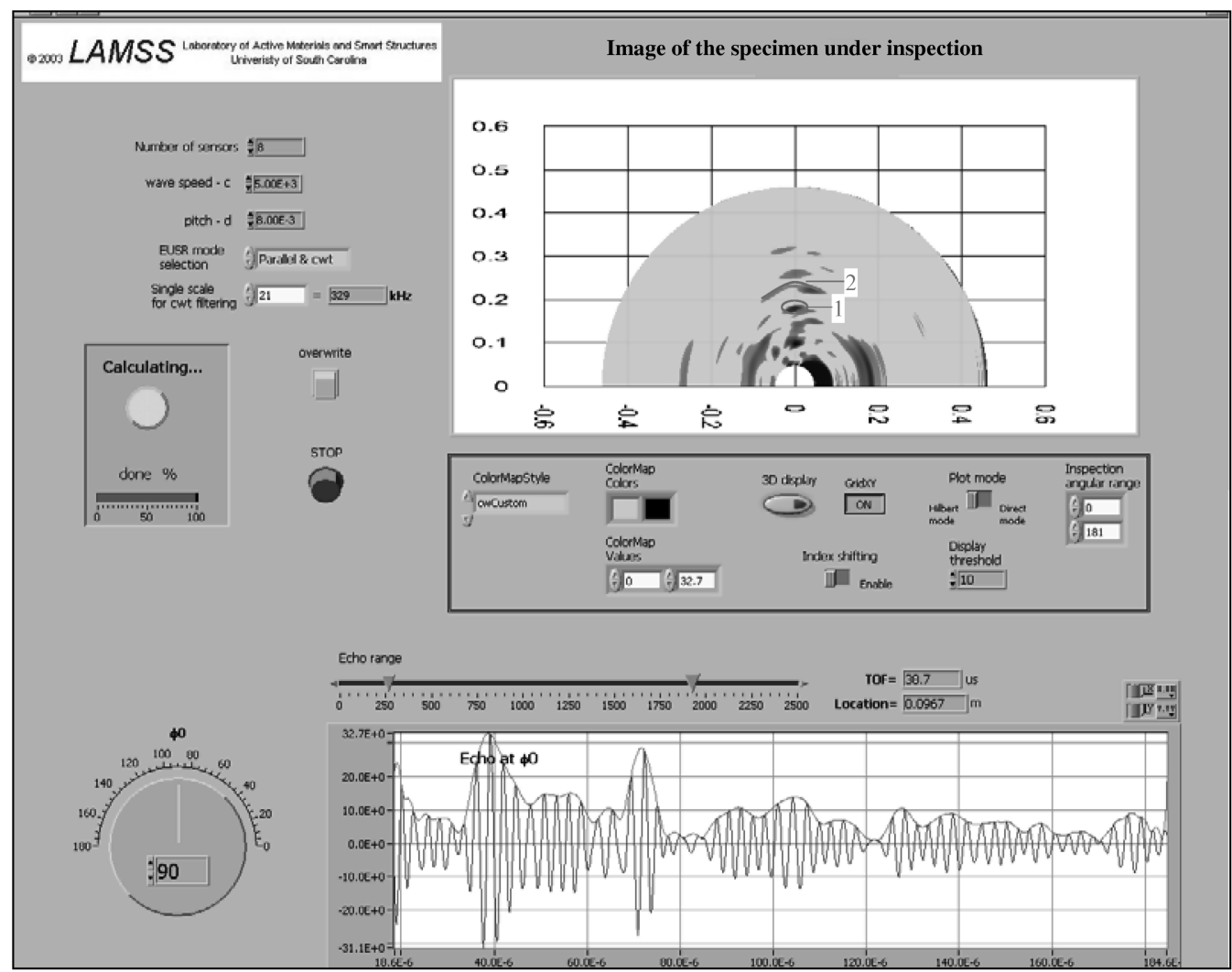

Fig. 21 EUSR inspection result of array no. 2, plate 1.

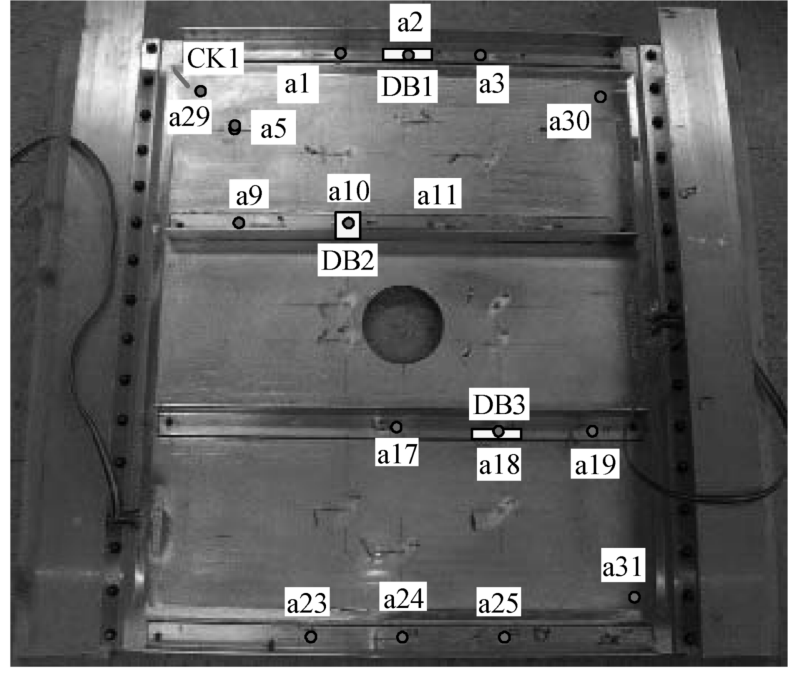

a)

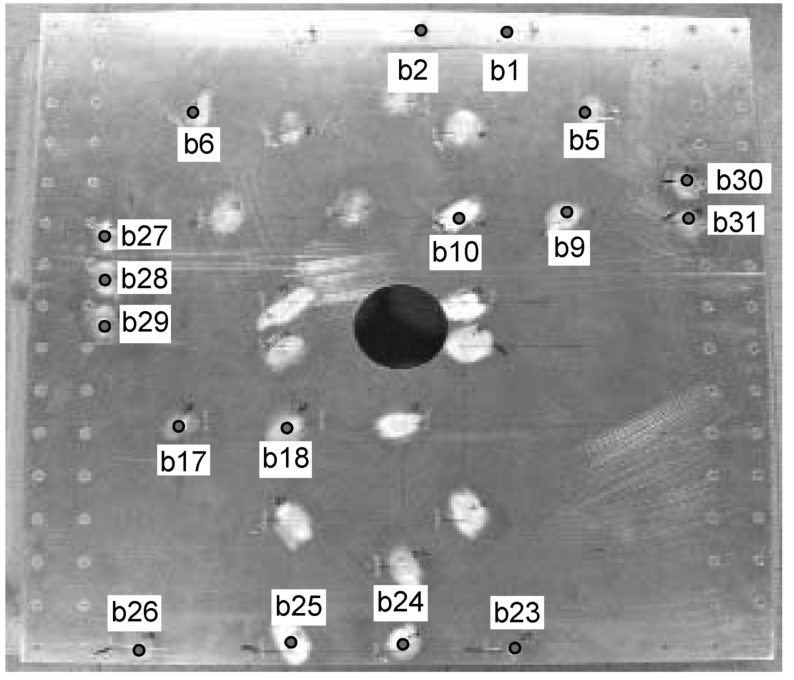

b)

Fig. 22 PWAS location on panel 1 for the E/M impedance tests: a) top face of panel 1, and b) bottom face of panel 1.

of using protective coating to minimize the ingression of adverse agents.

Another factor that can affect the performances of a sensor is the thickness of the bond layer. The bond layer can influence directly the dynamic response of the sensor. Not only the thickness of the bond layer, but also the properties of the adhesive itself play a role in the behavior of the sensor. Modeling of the bond layer (interaction with the host structure and the sensor) and the adhesive effects have been studied by several researchers and the results have been reported in the literature [22-24].

Two PWAS were attached to a testing sample skin to calculate the wave speed for the $A_{0}$ and $S_{0}$ Lamb modes. The pitch-catch method was used and a three-count sine smoothed burst signal was sent from PWAS no. 1 (the transmitter) to PWAS no. 2 (the receiver). After several trials, the optimum excitation frequency for the $A_{0}$ mode was chosen as $60 \mathrm{kHz}$, and for the $S_{0}$ mode, $330 \mathrm{kHz}$. The sent and received signals are shown in Fig. 9.

Using the information extracted from Fig. 10, the group wave speed was calculated as

$$
\begin{aligned}
& \Delta t_{A 0}=84.8 \mu \mathrm{s}, \quad \Delta t_{S 0}=28.6 \mu \mathrm{s}, \quad L=143 \mathrm{~mm} \\
& c_{A 0}=\frac{L}{\Delta t_{A 0}}=1.7 \mathrm{~mm} / \mu \mathrm{s}, \quad c_{S 0}=\frac{L}{\Delta t_{S 0}}=5 \mathrm{~mm} / \mu \mathrm{s}
\end{aligned}
$$


where $c_{A 0}$ is the group phase velocity of the $A_{0}$ mode, $c_{S 0}$ is the group phase velocity of the $S_{0}$ mode, $\Delta t$ is the time of flight, and $L$ is the distance between the two sensors.

To validate the transmission and reception of Lamb waves and to positively identify the reflections in the received signal, the pulseecho method was used. Knowing the location of the damage (middle circle) and the relative position of the edges of the plate from the two PWAS, as well as the group velocity, the reflections can be labeled in the time domain response (Figs. 11 and 12).

\section{B. Experiments with the Pitch-Catch Method}

In this section, the disbond detection using the pitch-catch method was investigated. The PWAS used for the pitch-catch method and the actual location of the sensors used on panel 1 is presented in Fig. 13.

The locations of the disbonds are presented in Fig. 13a: DB1 is located between PWAS a1 and PWAS a3, DB2 is located between PWAS a9 and PWAS a11, and DB3 is between PWAS a17 and PWAS a19. Disbonds DB1 and DB3 are $50.80 \times 12.70 \mathrm{~mm}$ and represent partial disbond of the stiffener, and DB2 is $25.40 \mathrm{~mm}^{2}$ and represents total disbond of the stiffener. The results for the disbonds DB1, DB2, and DB3 are presented in Fig. 14. They show the signals sent and received from sensors located on a stiffener with a disbond and the signal received by a sensor located on a stiffener without a disbond.

It can be seen from Fig. 14a that there is a strong difference between the wave traveling over a disbond and the same wave traveling over a good bond. For a better quantification of the damage present in the received signals, a damage index was developed. The damage index (DI) will take into consideration the energy of the wave traveling over a pristine area and the energy of the wave traveling over a disbonded area:

$$
\mathrm{DI}=1-\frac{\text { Energy }_{\text {pristine }}}{\text { Energy }_{\text {damage }}}= \begin{cases}0, & \text { no damage } \\ 1, & 100 \% \text { damage }\end{cases}
$$

Figure 15 shows that the DI increases going from an undamaged area to different types of disbonds and this is in accordance with an increase in the severity of the damage.

\section{Experiments with the Pulse-Echo Method}

In this section, the disbond detection using the pulse-echo method was investigated. The PWAS used for the pulse-echo method and the actual location of the sensors used on panel 1 is presented in Fig. 16:

For disbond detection using the pulse-echo method, a three-count smoothed sine burst at $330 \mathrm{kHz}$ was used to excite $S_{0}$ mode Lamb waves into the testing specimen. The results shown in Figs. 17 and 18 refer to the disbond DB2. For this case, the PWAS a7, a8, a20, and a21 were used. PWAS a7 is located close to the disbond DB2, whereas PWAS a8, a20, and a21 are located in a pristine area where no damage is present. The comparison of the signal received from the damage with the signals where there is no damage is presented in Fig. 17.

Figure 18 shows clear changes in the received signal (additional reflections) close to the damage. The presence of additional reflections is associated with echoes from the disbonded area.

\section{Experiments with the Embedded Ultrasonic Structural Radar}

The PWAS used for the embedded ultrasonic structural radar method and the actual location of the sensors on panel 1 is presented in Fig. 19.

Two phased arrays have been mounted on the top face of panel 1 . Each array consists of eight PWAS spaced at $1 \mathrm{~mm}$ intervals. The excitation frequency used in the experiment was $330 \mathrm{kHz}$ and the calculated group velocity was $5 \mathrm{~mm} / \mu$ s as shown in Sec. V.A. After the data were collected from the sensors, the parallel algorithm was used to construct the time-frequency domain signal. Next, the $330 \mathrm{kHz}$ component was extracted using continuous wavelet transform. The Hilbert transform was applied to the filtered signal to get its envelope. In the A-scan image in Fig. 20, the continuous wavelet transform (CWT) filtered signals at the dial indicated direction and the envelopes of the respective signals are shown. The two-dimensional images show the inspection result of the specific PWAS array.

The location of the crack with respect to array no. 1 is $50 \mathrm{~mm}$ perpendicular to the array which is the worst case possible because the echo from such a crack is equivalent to the echo of a hole with the diameter equal to the width of the slit, in this case 0.005 in. or

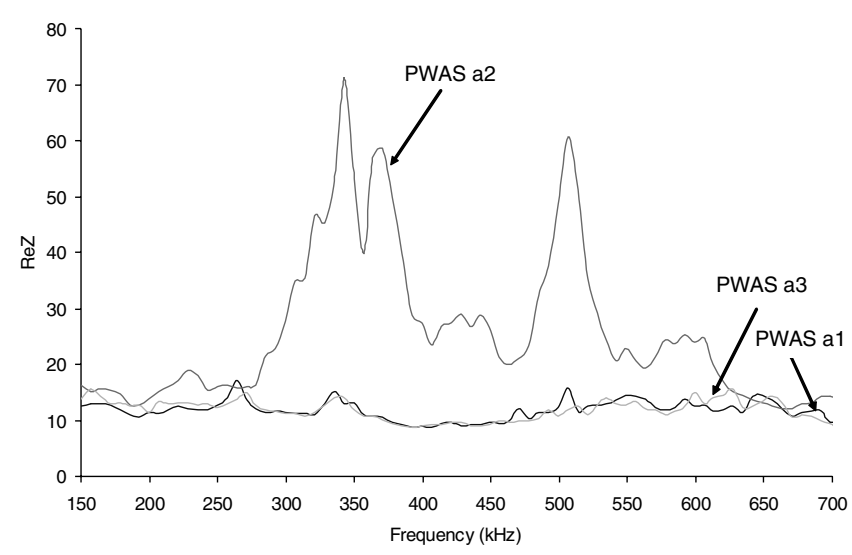

Fig. 23 E/M impedance method: resonant frequencies spectrum showing increased amplitude for the signal received at the sensor located on the top of disbond DB1 (PWAS a2).

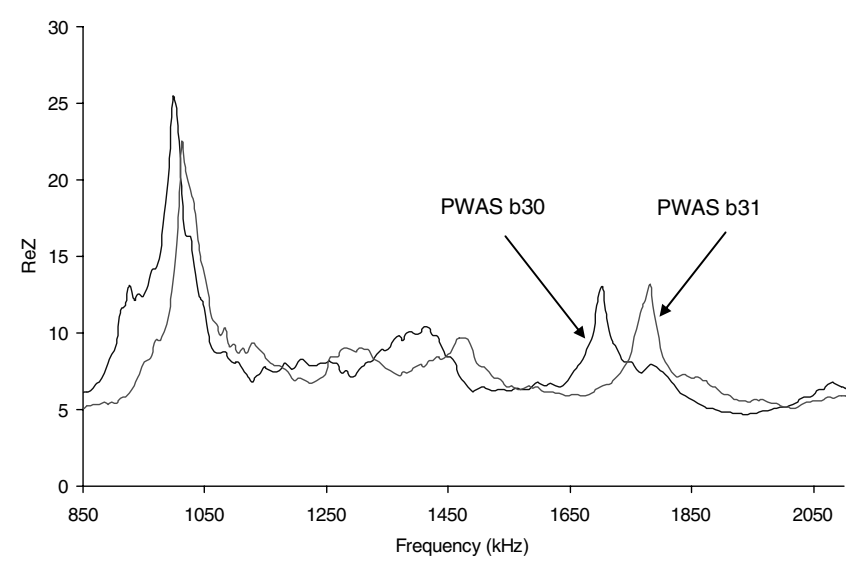

Fig. 24 E/M impedance method: resonant frequencies showing shifted peaks for corroded area CR1 (PWAS b30) vs undamaged area (PWAS b31).

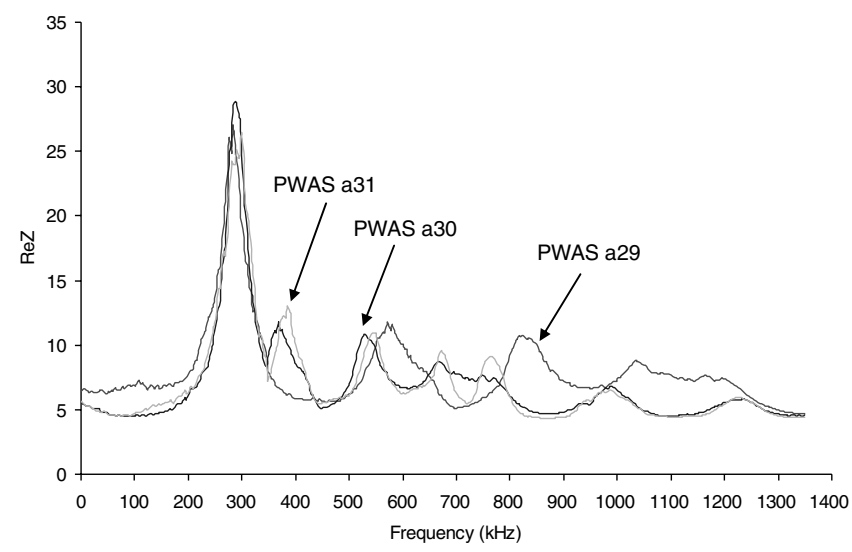

Fig. 25 E/M impedance method: resonant frequencies of the sensor close to the crack CK1 (PWAS a29) and the sensors in a pristine area (PWAS a30 and a31). 
Table 3 Summary of PWAS detection methods

\begin{tabular}{lcccc}
\hline \hline & \multicolumn{3}{c}{ Wave propagation } \\
\cline { 2 - 4 } Damage type & Pitch-catch & Pulse-echo & EUSR & Standing-wave E/M impedance \\
\hline Disbond & fair & good & good & good \\
Cracks & - & fair & fair & good \\
Corrosion & - & fair & - & fair \\
Crack under bolt & good & - & \\
\hline \hline
\end{tabular}

$0.13 \mathrm{~mm}$. Therefore, it is very hard to distinguish the echo on the twodimensional plot in Fig. 20. The location of the second damage with respect to array no. 2 is $1 \overline{70} \mathrm{~mm}$ parallel to the array. The middle hole has generated a strong reflection labeled as 1 in Fig. 21 . The centerline of the circle is $220 \mathrm{~mm}$ away from the array and the circle is symmetric to the perpendicular centerline of both the circle and the array. From the asymmetric image labeled as 2 in Fig. 21, we can generally tell there may be some disturbance resulting from damage around the circumference at the centerline.

\section{E. Experiments with the Electromechanical Impedance Method}

The PWAS used for the E/M impedance method and the actual location of the sensors used on panel 1 is presented in Fig. 22. The E/ $\mathrm{M}$ impedance method was used to detect disbonds, cracks, and corrosions. The results are presented in Figs. 23 and 24. The impedance spectrum from PWAS a1, a2, and a is presented in Fig. 23. It can be seen that the resonant spectrums of the signals from PW $\overline{A S}$ a1 and a3 located on an area with good bond are almost identical. The resonant spectrum from PWAS a2 located on the disbond DB1 is very different, showing new strong resonant peaks associated with the presence of the disbond.

The E/M impedance method also showed good results in detecting corrosion. In Fig. 25 the resonant spectrum for the sensors PWAS b30 (corroded area) and PWAS b31 (undamaged area) are presented. The shift in the resonant frequency peak for the PWAS b30 is very clear, which is an indication of a structural change due to the corrosion.

The same phenomenon of shifted and prominent resonant frequencies is noticeable in the crack CK1 detection shown in Fig. 25. PWAS a30 and PWAS b31 show a consistent resonant spectrum and PWAS a29 presents the features mentioned in the preceding paragraphs.

\section{Conclusions}

This paper has presented the results of experimental investigations conducted to demonstrate the possibility of using piezoelectric wafer active sensors for structural health monitoring with space applications. The objective of this work was to show feasibility of key structural health monitoring technologies applied to realistic structural components for space applications. This work has been conducted in collaboration with NextGen Aeronautics, Inc., who was responsible for the general management of the project and for the manufacturing of the spacecraft panel specimens.

The experimental results presented in this paper indicate that PWAS-based structural health monitoring can be successfully applied to the damage detection in metallic specimens typical of current spacecraft structures. The comparison of various damage types and various detection methods employed in our study indicates that no single method is capable of universally detecting all the damage types that can appear in a typical spacecraft structure. To assist in this interpretation, Table 3 gives a summary of how various damage detection methods fared in relation with the various damage types considered in our tests. From Table 3, one sees that some methods are more appropriate for certain damage types and less appropriate for other damage types. The results are based on nearfield and medium-field damage detection for a specific damage size. The use of far-field damage detection was not practical in our studies due to the relatively small size of our specimens.
Hence, the main conclusion of our study is that a multimethod approach is the advisable course of action for detecting a multitude of damage types as considered in our study. This allows us to conclude that successful damage detection can be achieved by using, in combination, both traveling waves methods (pitch-catch, pulseecho, and phased arrays), as well as standing waves methods (electromechanical impedance method). For most cases, most of these damage detection approaches can be achieved with the same installation of PWAS transducers into the structure, which illustrates the versatility of PWAS-based structural health monitoring strategies.

\section{Acknowledgments}

The financial support of the NASA STTR T7-02 through NextGen Aeronautics, Inc., and of the National Science Foundation award CMS 0408578, Shih Chi Liu, program director, are gratefully acknowledged.

\section{References}

[1] Giurgiutiu, V., and Zagrai, A., "Characterization of Piezoelectric Wafer Active Sensors," Journal of Intelligent Material Systems and Structures, Vol. 11, No. 12, 2000, pp. 959-976.

[2] Giurgiutiu, V., Redmond, J., Roach, D., and Rackow, K., "Active Sensors for Health Monitoring of Aging Aerospace Structures," Proceedings of the SPIE Conference on Smart Structures and Integrated Systems, Vol. 3985, International Society for Optical Engineering, Bellingham, WA, 2000, pp. 294-305.

[3] Giurgiutiu, V., and Cuc, A., "Embedded NDE for Structural Health Monitoring, Damage Detection, and Failure Prevention," The Shock and Vibration Digest, Sage Publ., Vol. 37, No. 2, March 2005, pp. 83-105. doi: $10.1177 / 0583102405052561$

[4] Cuc, A., and Giurgiutiu, V., "Propagation of Guided Lamb Waves in Bonded Specimens Using Piezoelectric Wafer Active Sensors," SPIE's 13th International Symposium on Smart Structures and Materials and 11th International Symposium on NDE for Health Monitoring and Diagnostics, International Society for Optical Engineering Paper 617440, Feb.-March 2006.

[5] Diamanti, K., Soutis, C., and Hodgkinson, J. M., "Non-Destructive Inspection of Sandwich and Repaired Composite Laminated Structures," Composites Science and Technology, Vol. 65, No. 13, 2005, pp. 2059-2067.

doi:10.1016/j.compscitech.2005.04.010

[6] Diamanti, K., Hodgkinson, J. M., and Soutis, C., "Detection of LowVelocity Impact Damage in Composite Plates Using Lamb Waves," Structural Health Monitoring, Vol. 3, No. 1, 2004, pp. 33-41.

[7] Diaz Valdes, S. H., and Soutis, C., "Real-Time Non-Destructive Evaluation of Fibre Composite Laminates Using Low-Frequency Lamb Waves," Journal of the Acoustical Society of America, Vol. 111, No. 5, 2002, pp. 2026-2033. doi: $10.1121 / 1.1466870$

[8] Moulin, E., Assaad, J., Delebarre, C., Kaczmarek, H., and Balageas, D., "Piezoelectric Transducers Embedded in a Composite Plate: Application to Lamb Wave Generation," Journal of Applied Physics, Vol. 82, No. 5, 1997, pp. 2049-2055. doi: $10.1063 / 1.366015$

[9] Lin, X., and Yuan, F. G., "Diagnostic Lamb Waves in an Integrated Piezoelectric Sensor/Actuator Plate: Analytical and Experimental Studies," Smart Materials and Structures, Vol. 10, Aug. 2001, pp. 907-913. doi:10.1088/0964-1726/10/5/307

[10] Liu, T., Veidt, M., and Kitipornchai, S., "Modeling the Input-Output Behavior of Piezoelectric Structural Health Monitoring Systems for 
Composites Plates," Smart Materials and Structures, Vol. 12, No. 5, 2003, pp. 836-844. doi:10.1088/0964-1726/12/5/021

[11] Lee, B. C., and Staszewski, W. J., "Modeling of Lamb Waves for Damage Detection in Metallic Structures, Part 1: Wave Propagation," Smart Materials and Structures, Vol. 12, No. 5, Oct. 2003, pp. 804814. doi:10.1088/0964-1726/12/5/018

[12] Lee, B. C., and Staszewski, W. J., "Modeling of Lamb Waves for Damage Detection in Metallic Structures, Part 2: Wave Interactions with Damage," Smart Materials and Structures, Vol. 12, No. 5, Oct. 2003, pp. 815-824. doi: $10.1088 / 0964-1726 / 12 / 5 / 019$

[13] Lin, M., Kumar, A., Qing, X., and Beard, S., "Advances in Utilization of Structurally Integrated Sensor Networks for Health Monitoring in Commercial Applications," Proceedings of SPIE: The International Society for Optical Engineering, Vol. 4701, International Society for Optical Engineering, Bellingham, WA, 2002, pp. 167-176.

[14] Giurgiutiu, V., "Lamb Wave Generation with Piezoelectric Wafer Active Sensors for Structural Health Monitoring," Proceedings of SPIE: The International Society for Optical Engineering, Vol. 5056, International Society for Optical Engineering, Bellingham, WA, 2003, pp. 111-122.

[15] Sheng, L., and Kapania, R. K., "Extensive Experiments on Genetic Algorithms for the Optimization of Piezoelectric Actuator Locations," AIAA Journal, Vol. 44, No. 12, 2006, pp. 2904-2918. doi:10.2514/1.19181

[16] Bland, S. M., and Kapania, R. K., "Sensor Placement Optimization for Lamb Wave Based Structural Health Monitoring," Collection of Technical Papers: 11th AIAA/ISSMO Multidisciplinary Analysis and Optimization Conference," Vol. 4, AIAA, Reston, VA, 2006, pp. 2263-2280

[17] Yu, L., and Giurgiutiu, V., "Multi-Damage Detection with Embedded Ultrasonic Structural Radar Algorithm Using Piezoelectric Wafer Active Sensors Through Advanced Signal Processing," SPIE's 12th International Symposium on Smart Structures and Materials and NDE for Health Monitoring and Diagnostics, Health Monitoring and Smart
NDE of Structural and Biological Systems Conference, International Society for Optical Engineering Paper 5768-48, 2005.

[18] Giurgiutiu, V., and Bao, J., "Embedded Ultrasonic Structural Radar with Piezoelectric Wafer Active Sensors for the NDE of Thin-Wall Structures," Proceedings of the ASME Nondestructive Evaluation Engineering Division, Vol. 23, American Society of Mechanical Engineers, Fairfield, NJ, 2002, pp. 31-38.

[19] Elliott, D. F., Handbook of Digital Signal Processing: Engineering Applications, Academic Press, New York, 1987.

[20] Giurgiutiu, V., "New Results in the Use of Piezoelectric Wafer Active Sensors for Structural Health Monitoring," 46th AIAA/ASME/ASCE/ AHS/ASC Structures, Structural Dynamics \& Materials Conference and 13th AIAA/ASME/AHS Adaptive Structures Conference, AIAA Paper 2005-2191, 2005

[21] Blackshire, J. L., Giurgiutiu, V., Cooney, A., and Doane, J., "Characterization of Sensor Performance and Durability for Structural Health Monitoring," SPIE's 12th International Symposium on Smart Structures and Materials and 10th International Symposium on NDE for Health Monitoring and Diagnostics, Advanced Sensor Technologies for Nondestructive Evaluation and Structural Health Monitoring Conference, International Society for Optical Engineering Paper 577008, 2005.

[22] Jiao, D., and Rose, J. L., "Ultrasonic Interface Layer Model for Bond Evaluation," Journal of Adhesion Science and Technology, Vol. 5, No. 8, pp. 631-646, 1991

[23] Callens, D., Bruneel, C., and Assaad, J., "Matching Ultrasonic Transducer Using Two Matching Layers Where One of Them is Glue," NDT \& E International: Independent Nondestructive Testing and Evaluation, Vol. 37, No. 8, 2004, pp. 591-596. doi:10.1016/j.ndteint.2004.03.005

[24] Giurgiutiu, V., and Lyshevski, S. E., Micromechatronics: Modeling, Analysis, and Design with MATLAB, CRC Press, Boca Raton, FL, ISBN 084931593X, 2004, p. 856.
C. Cesnik Associate Editor 